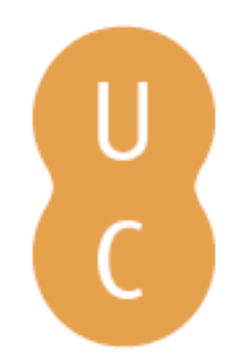

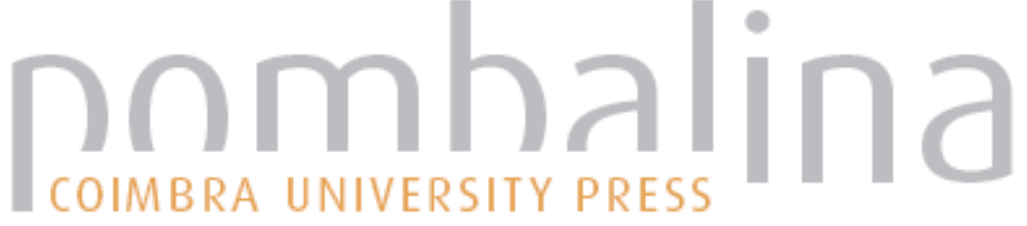

\section{Modelação de redes territoriais: o caso do Interreg III C}

\author{
Autor(es): $\quad$ Mendes, Ana
}

Publicado por: Imprensa da Universidade de Coimbra

URL

persistente: $\quad$ URI:http://hdl.handle.net/10316.2/31141

DOI: $\quad$ DOI:http://dx.doi.org/10.14195/978-989-26-0244-8_62

Accessed : $\quad$ 26-Apr-2023 12:05:25

A navegação consulta e descarregamento dos títulos inseridos nas Bibliotecas Digitais UC Digitalis, UC Pombalina e UC Impactum, pressupõem a aceitação plena e sem reservas dos Termos e Condições de Uso destas Bibliotecas Digitais, disponíveis em https://digitalis.uc.pt/pt-pt/termos.

Conforme exposto nos referidos Termos e Condições de Uso, o descarregamento de títulos de acesso restrito requer uma licença válida de autorização devendo o utilizador aceder ao(s) documento(s) a partir de um endereço de IP da instituição detentora da supramencionada licença.

Ao utilizador é apenas permitido o descarregamento para uso pessoal, pelo que o emprego do(s) título(s) descarregado(s) para outro fim, designadamente comercial, carece de autorização do respetivo autor ou editor da obra.

Na medida em que todas as obras da UC Digitalis se encontram protegidas pelo Código do Direito de Autor e Direitos Conexos e demais legislação aplicável, toda a cópia, parcial ou total, deste documento, nos casos em que é legalmente admitida, deverá conter ou fazer-se acompanhar por este aviso.

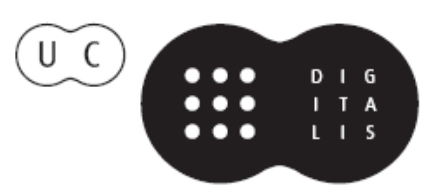




\section{TRUNFOS DE UMA}

\section{EOGRAFIA ACIVA}

\section{DESENVOLVIMENTO LOCAL,}

AMBIENTE,

ORDENAMENTO

E TECNOLOGIA

Norberto Santos

Lúcio Cunha

COORDENAÇÃO 
Ana Mendes

CEG-IGOT, UL

MODELAÇÃO DE REDES TERRITORIAIS: O CASO DO INTERREG III C

\section{INTRODUÇÃO}

Os territórios estão em constante mudança. Cada vez mais as problemáticas territoriais extravasam os limites administrativos e fronteiriços. Deste modo, considera-se importante que o pensamento e a prática do planeamento decorram de uma forma mais alargada, envolvendo os múltiplos actores oriundos das mais variadas áreas do conhecimento, com sensibilidades territoriais distintas.

Este estudo, pretende proporcionar uma perspectiva sobre a estrutura espacial do espaço Interreg no contexto das redes territoriais, no âmbito do programa Interreg III C, nos quais estiveram envolvidos parceiros portugueses e é parte integrante do projecto de investigação COOPTER - Dos Territórios em Rede à Cooperação Territorial-Dinâmicas Espaciais e Inovação Processual em Portugal Continental (PTDC/GEO/71874/2006). O principal objectivo prende-se com a quantificação e cartografia da geografia da Cooperação Territorial enquadrada no programa Interreg III C, baseada na análise dos projectos e das redes de cooperação. Pretende-se aplicar a análise de redes sociais aos projectos de cooperação em análise, de forma a analisar as relaçóes existentes entre parceiros envolvidos nos projectos de cooperação.

A comunicação irá focar-se em duas dimensôes analíticas da cooperação territorial, são elas agentes (1) e as redes de cooperação (2). Os primeiros vão ser analisados estatisticamente e as redes de cooperação serão analisadas através da aplicação da análise das redes sociais, de forma a explorar o potencial da análise de redes sociais (Social network analysis) na avaliaçáo da estrutura de cooperação do Interreg III C. Nesta análise serão utilizados dados referentes aos projectos Interreg III C financiados pelo $3^{\circ}$ Quadro Comunitário de Apoio.

\section{COOPERAÇÃO TERRITORIAL}

$\mathrm{Na}$ actualidade as preocupaçóes com os modelos de governança territorial, com as políticas públicas, com o desenvolvimento territorial, e em particular com a coesão territorial condicionam a intervenção pública dos diferentes stakeholders e geram custos desnecessários de não-coordenação das políticas Europeias e nacionais, sendo, necessário identificar e ter um conhecimento detalhado da diversidade territorial para podermos agir de uma forma sustentada. 
A cooperação territorial é vista como um processo que potencia essa mesma coesão, uma vez que, os três grandes pontos da política de coesáo são a eficiência e efectividade da política, a competitividade regional e o emprego e a cooperação territorial.

Efectivamente, a conjugação de acçôes no domínio da cooperação territorial são determinantes para uma estratégia de desenvolvimento territorial eficaz, na medida em que promovem a necessária interacção positiva entre agentes territoriais e boas práticas.

Os objectivos da cooperaçáo territorial no contexto europeu resumem-se a aproximação dos espaços, promoção do desenvolvimento de um território Europeu integrado e balançado por via das redes de cooperaçáo e fortalecer as prioridades da União Europeia - as agendas de Lisboa e Gutemburgo.

Do nosso ponto de vista, num sentido lato, a cooperaçáo pode ser tida em conta como uma ferramenta para a prossecução do desenvolvimento e da competitividade dos territórios.

Muitos autores falam do valor acrescentado da cooperaçáo territorial. Colomb (2007, pp. 363), refere que «Trabalhar em cooperação produz conhecimento, inovação e novas formas de actuar no território». Para Davies «O futuro do planeamento na Europa [...] assenta no crescimento de uma aprendizagem mútua e da cooperação governamental ao nível regional e local a partir da qual surgirá uma convergência progressiva das políticas e práticas de planeamento» (Davies 1994, p.69 em Rivolin, Faludi 2005, p.196).

Entende-se a cooperação territorial como uma acção com diversas intensidades, diferentes objectivos e parceiras. Esta pode ser uma simples troca de experiências ou o desenho e implementação de uma estratégia comum. Neste sentido, Colomb (2007) divide a cooperação territorial em 5 tipos: (1) troca de experiências (2) co-realização de uma acção transnacional / investimento, (3) produção e execução conjunta de uma estratégia espacial transnacional, (4) partilha de ferramentas e recursos na resoluçáo de um problema comum, e (5) teste ou transferência de diferentes abordagens na resolução de um problema comum.

Assim, o conceito de cooperação territorial pode ser vista como o acto de agir conjuntamente ou interagir no sentido de atingir um objectivo comum com impactos territoriais.

\section{Interreg III C}

Quando se fala do programa comunitário Interreg III C está-se a fazer referência a um programa da UE que ajuda as regióes da Europa a formar parcerias para trabalhar em conjunto em projectos comuns. Ao partilhar conhecimentos e experiências, essas parcerias permitem às regióes envolvidas desenvolver novas soluçôes para os desafios económicos, sociais e ambientais.

A Comissão Europeia considera que a cooperação inter-regional permite a regiōes não contíguas entrar em contacto umas com as outras e criar relaçóes, possibilitando o intercâmbio de experiências e o estabelecimento de redes que apoiem o desenvolvimento equilibrado, harmonioso e sustentável da União Europeia e de países terceiros (CCE 2001).

Este programa pretende essencialmente melhorar a eficácia das políticas e instrumentos de desenvolvimento regional e coesão, e possibilitar a transferência de ferramentas e a partilha de experiências entre as regióes europeias através da troca de informaçóes e de know-how. ${ }^{1}$

\footnotetext{
${ }^{1}$ http://www.interreg3c.net/sixcms/detail.php?id=310
} 
As áreas de cooperação elegíveis correspondem a todos os países membros da UE, adicionando a Noruega e a Suíça e ainda outros países que não pertencem à UE.

\section{MATERIAl E MÉTODOS}

No ponto anterior foram feitas algumas reflexóes conceptuais sobre a Cooperação Territorial, em particular sobre o conceito de Cooperação Territorial no contexto do Interreg III C. No presente ponto é feita uma apresentação dos materiais e métodos utilizados na prossecução dos objectivos apresentados previamente.

Neste artigo, a Cooperação Territorial aborda-se através da análise dos projectos de cooperação que decorreram no âmbito do Interreg III no período de 2000-2006. Foi seleccionada a vertente de cooperação inter-regional visto que considera-se ser a que melhor caracteriza a disseminação de interacçóes entre parceiros e onde as redes são mais livremente criadas. Neste sentido, de um total de 208 operaçóes de cooperação inter-regional, foram analisados 57 projectos (todos os projectos do Interreg IIIC onde entra um parceiro português), uma vez que pretende-se analisar a cooperação territorial ao nível dos parceiros portugueses. Note-se que estes 57 projectos correspondem a cerca de 600 parceiros nos projectos, a um total de 38 países envolvidos e a 180 regiôes envolvidas nos projectos de cooperação.

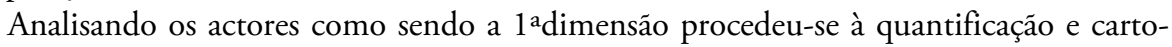
grafia dos mesmos, envolvidos nos 57 projectos de cooperação, deste modo, foi possível caracterizar a territorialidade dos agentes em termos do número de vezes que participam num projecto de cooperação, o número de relaçóes que cada um tem com outros agentes e o custo total dos projectos em que estiveram envolvidos. Esta análise foi realizada em ambiente SIG, procedendo-se à modelação dos dados espaciais. Esta análise permitiu obter uma representação simplificada da realidade, a partir da qual se podem explicar as características da cooperação territorial.

A rede de cooperação é a segunda dimensão analisada, neste sentido, foi utilizada a metodologia das análises de redes sociais, que permitiu conhecer as interacçóes entre as regiôes que participam nos 57 projectos de cooperação inter-regional. Neste contexto, foi necessário elaborar uma matriz de informação referente às relações existentes entre regióes. A matriz criada era uma matriz quadrada, em que o número de linhas é igual ao número de colunas, apresentando a particularidade de ser idêntica, ou seja, o nome das linhas era igual ao nome das colunas. A matriz criada era simétrica (os valores acima da diagonal principal eram iguais aos valores abaixo da diagonal principal) esta característica gera fluxos bidireccionais entre as unidades de análise (países e regióes). Para a criação e visualização de rede utilizou-se o software UCINET (Borgatti et al. 2005).

A principal fundamentaçáo do método das Análise de Redes Sociais indica que as estruturas sociais podem ser descritas em termos dos atributos individuais, mas também em termos de relaçóes multi-direccionais. A estrutura de uma rede é determinada pela configuração das relaçóes presentes e ausentes entre os nós e pode variar de uma estrutura isolada, onde nenhum nó é conectado, a uma rede saturada, totalmente ligada.

A análise de redes sociais deve muito das suas ferramentas quantitativas à teoria dos grafos, utilizando as medidas estatísticas para descrever as estruturas das redes. Neste con- 
texto, estas medidas podem ser utilizadas para descrever diferentes fenómenos sociais, como as relaçóes entre e dentro de instituiçôes, relaçóes entre cidades, entre outros temas.

Para medir e avaliar a relação da rede territorial, no contexto do Interreg III, seleccionaram-se os indicadores estruturais, que parecem ser os mais adequados. Assim, as medidas seleccionadas na caixa de ferramenta de análise de rede foram a densidade da rede e a centralidade dos actores (países).

A densidade da rede obtém-se através da divisão do número de relações existentes pelo número de relaçóes possíveis na rede.

O grau de centralidade permite avaliar a posição de cada actor na rede e pode ser interpretado como a proeminência de um actor no grupo social (Brandes, Kenis et al., 2003). Devido a este ponto de vista comum sobre a interpretaçáo da centralidade, considera-se esta, como uma das medidas mais adequadas para representar os padróes espaciais da cooperação no espaço europeu.

A última parte do trabalho é composta pelas consideraçôes finais, onde foi feita uma reflexão crítica da aplicação da análise das redes sociais aos projectos de cooperação interregional no âmbito do Interreg III C, nos quais existiram parceiros portugueses.

\section{RESUlTADOS E DisCUSSÃO}

No ponto anterior foi explicitada a metodologia aplicada neste artigo, o presente ponto foca-se na apresentação e discussão dos resultados obtidos.

Neste sentido, analisam-se os agentes de cooperação através de quatro parâmetros: (1) $\mathrm{n}^{\mathrm{o}}$ de projectos de cooperação, (2) no de parceiros envolvidos nos projectos de cooperação, (3) custo total dos projectos de cooperação e (4) relaçóes entre agentes. Os resultados são analisados a duas escalas distintas, primeiro é feita uma análise a nível da NUTS 1 e em seguida ao nível da NUTS II.

Assim, pela análise do mapa no 1 constata-se que são os parceiros franceses, espanhóis e holandeses que mais participam nos 57 projectos do Interreg III C onde Portugal coopera, em termos de chefia dos projectos. Neste sentido, são os parceiros chefes de fila dos projectos originários de França, Espanha e Holanda que mais se relacionam com outros parceiros, apresentando a França 200 relaçóes com outros países, a Espanha 82 relaçóes e a Holanda 83 relaçóes. Efectivamente, a França é caracterizada por ser o país em que existe um maior número de parceiros - chefes de fila, que pertencem a projectos de grande dimensão simultaneamente em número de parceiros e orçamento (fig. 1 e 2). Apesar de a Espanha se encontrar praticamente envolvida no mesmo número de projectos que a França, estes são na sua maioria de menor dimensão, representando metade do custo total dos projectos em que a França está envolvida (fig. 1 e 2). Já os parceiros - chefes de fila sediados na Holanda são caracterizados por se envolverem em redes de cooperação mais alargadas, em comparaçáo com os parceiros espanhóis, embora, os projectos onde cooperam não apresentem um valor orçamental muito elevado, comparativamente aos parceiros mencionados.

Ao refinarmos a análise por região, constata-se uma "readaptação» espacial do padrão de cooperação territorial no âmbito do Interreg III C. Pode afirmar-se que os parceiros chefes de fila, sediados na regiáo francesa de Provença-Alpes-Costa Azul, têm um peso importante no contexto dos projectos de cooperaçáo do Interreg III C, em que os 4 agentes chefes de fila sediados nesta regiáo, correspondem a um total de 47 parceiros de cooperação e a um total de 
43 relaçóes possíveis entre os parceiros. Castela e Leão, em Espanha e o Norte, em Portugal são as regiốes com o segundo maior número de parceiros. Mas enquanto a regiáo Norte detém um maior número de parceiros chefes de fila envolvidos nesses projectos, a região de Castela e Leão é caracterizada por ter projectos com um orçamento mais elevado. As regiôes de Andaluzia, na Espanha e Holanda do Sul, na Holanda são regióes representadas por um total de dois projectos no universo de projectos do Interreg III C em que Portugal foi parceiro. Os projectos sediados na regiáo Holanda do Sul são caracterizados por envolverem um maior número de parceiro e por disporem de um orçamento mais elevado.

Análise de Redes

Análise de redes sociais é uma ferramenta que permite conhecer as interacçóes em qualquer classe de indivíduos. Neste caso, preocupamo-nos em conhecer a estrutura das interacçóes dos actores no contexto da cooperação territorial ao abrigo do programa Interreg III C, ao nível das regióes. A estrutura da rede pode ser analisada com recurso a diversos indicadores, dependendo dos resultados pretendidos da análise.

A rede de relação de países por projectos foi construída através da agregação de parceiros com base na sua localização geográfica. A matriz resultante de um total de 14 países e 57 projectos foi transformada numa matriz de adjacência, aplicando o mesmo procedimento usado para a rede de parceiros. Apesar de as redes possuírem uma hierarquia interna (chefe de fila e outros parceiros), todos os parceiros envolvidos na rede foram tratados de igual forma, uma vez que é de difícil recolha a estrutura interna de cada rede.

A densidade da rede e as medidas de centralidade foram aplicadas a um subconjunto da matriz de dados original, sendo caracterizada pela existência de parceiros com pelo menos 7 ligações entre eles, representando a média de parceiros por projecto de cooperação.

Deste modo, a figura 1 espelha o grafo que representa a rede de cooperaçáo dos projectos, no âmbito do programa Interreg III C, nos quais existiram parceiros portugueses.

Esta rede de interacções é composta por 30 nós e 300 relações (vértices) de 899 relaçôes possíveis, sendo a densidade da rede de 33,3\%.

O grau de centralidade de cada actor (fig. 7) expressa o número de vezes que cada país se relaciona com outro país. A Itália é o país que mais relaçóes têm com os outros países (25 interacçóes). A França apresenta-se como o segundo país com o maior grau de centralidade, seguida por Portugal, Espanha e o Reino Unido que apresenta o maior valor de centralidade. A Suíça, a Noruega e a Eslovénia são os países que têm um número de relaçôes com outros países igual a dois, tendo um grau de centralidade muito baixo. Marrocos é o país com o menor grau de centralidade, na medida em que se relaciona apenas com a França.

A utilização de redes sociais para a análise das relaçóes entre parceiros do Interreg III C mostrou-se útil para a caracterização da rede de cooperação, uma vez que permitiu conhecer graficamente as interacçóes entre as regióes e permitiu ainda interpretar a importância da rede e dos países que constituem a rede. Este tipo de estudo torna-se fundamental na análise e compreensão das redes territoriais, que existem no contexto da cooperação territorial, de forma a compreender as dinâmicas espaciais existentes. Em particular, é essencial perceber as características das redes de cooperação dos agentes portugueses de forma a melhorar futuras acçóes deste tipo no contexto nacional. 


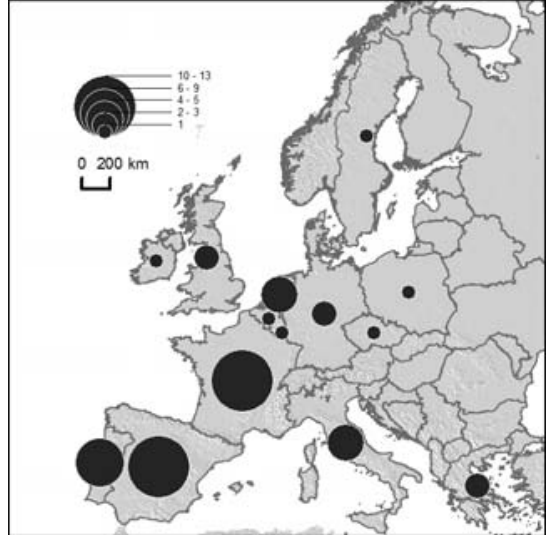

Figura 1 - Número de projectos no âmbito do Interreg III, por país

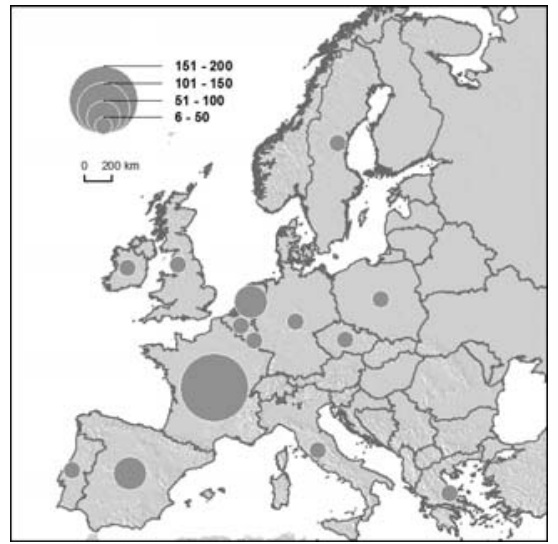

Figura 3 - Relaçóes do país com outros países no âmbito do Interreg III C, por país

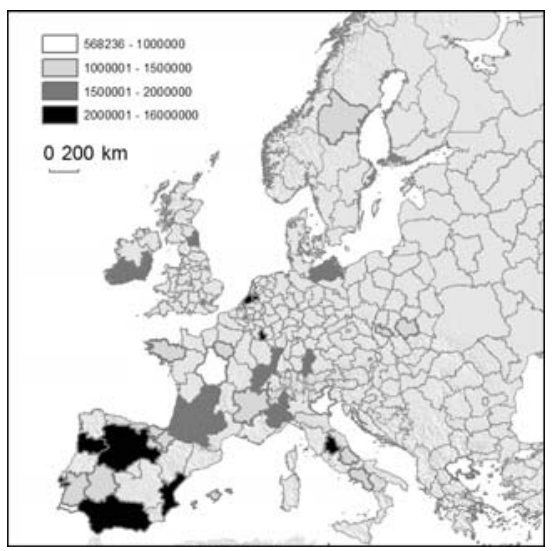

Figura 5 - Custo total dos projectos no âmbito do Interreg III C, por regiáo

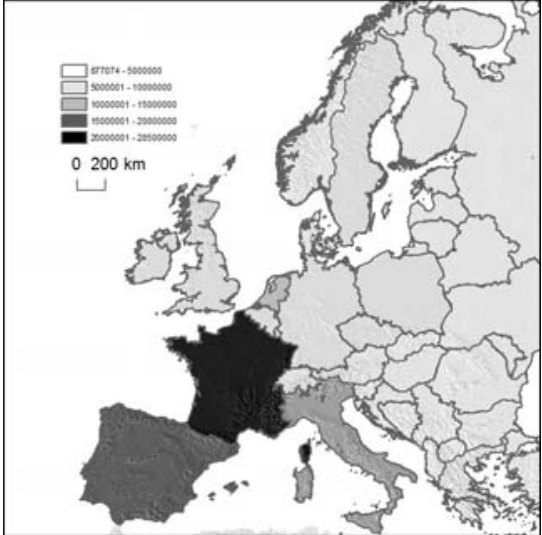

Figura 2 - Custo total dos projectos no âmbito do Interreg III C, por país

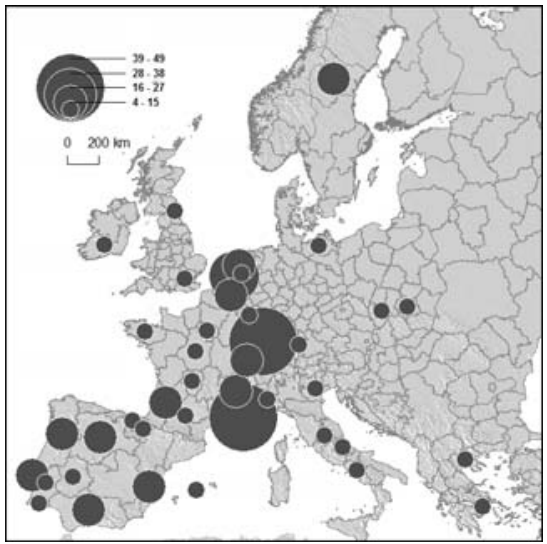

Figura 4 - Número de projectos no âmbito do Interreg III C, por regiáo

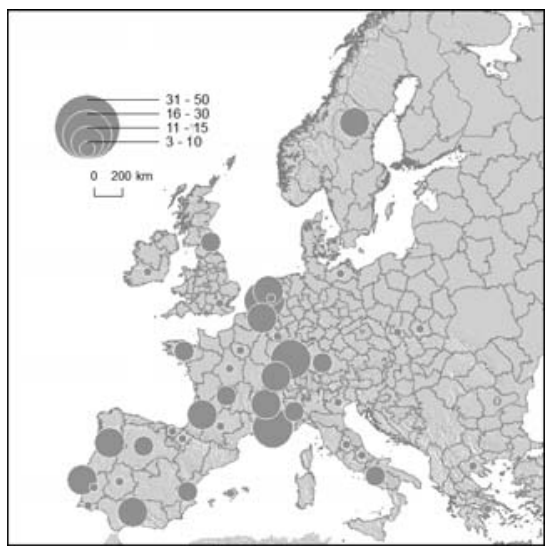

Figura 6 - Relaçóes do país com outros países no âmbito do Interreg III C, por região 


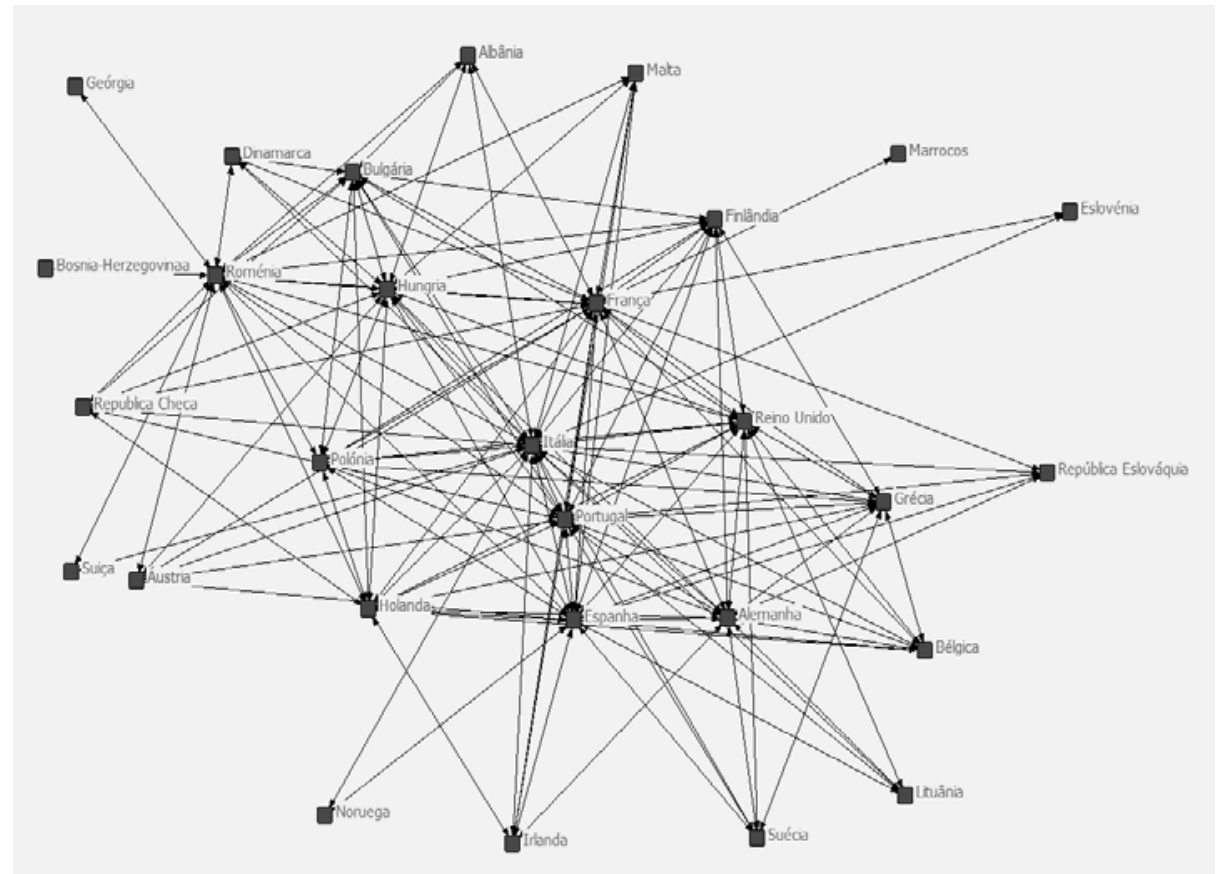

Figura 7 - Grafo da rede de cooperação

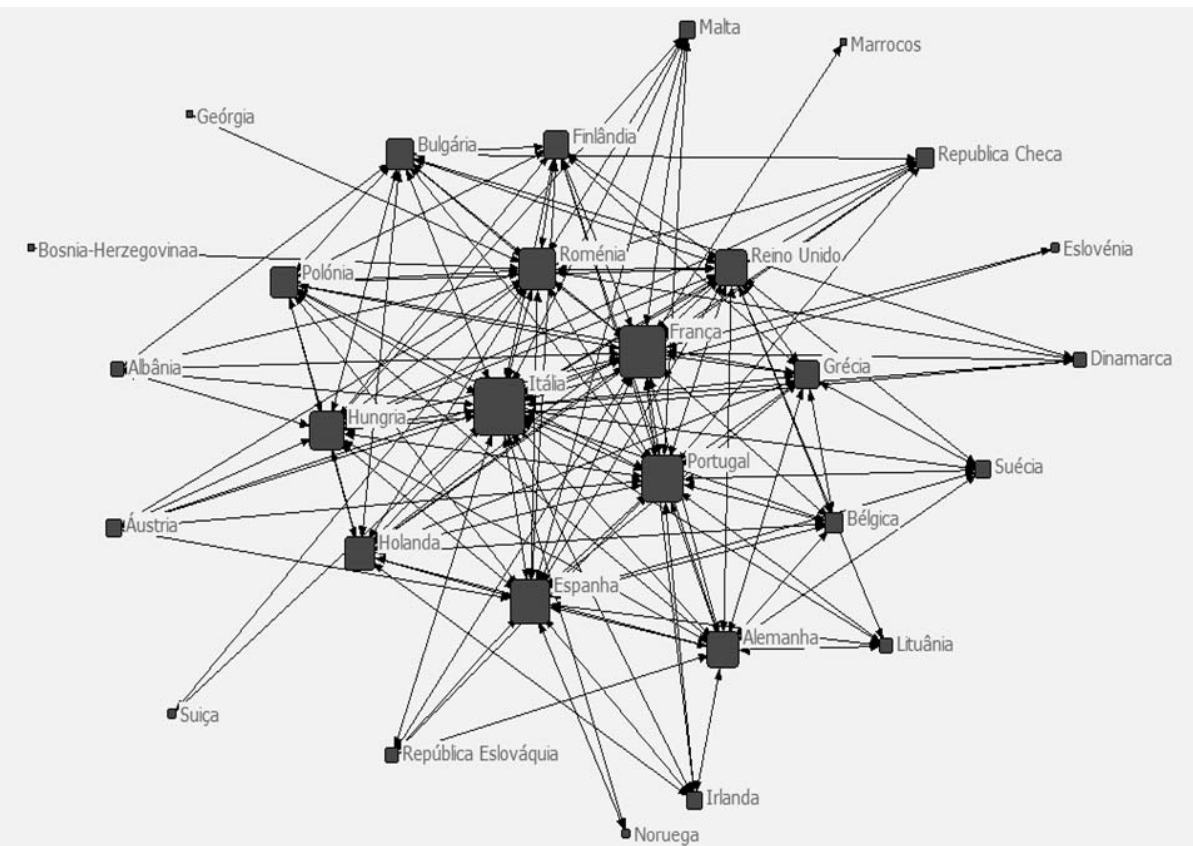

Figura 8 - Representação dos nós pelo seu grau de centralidade 
No entanto, é necessário ter presente que o simples facto de se estar a representar graficamente as interacçóes de um grupo de indivíduos nem sempre é suficiente para estabelecer uma análise em profundidade das características de cada agente dentro da rede.

A diversidade de informação disponível limitou a análise, visto que esta seria muito mais rica se existisse informação relativa ao tipo de actor envolvido na rede, à temática da cooperaçáo e ainda ao tipo de rede. Seria ainda mais interessante para a construção da rede a conjugação de todas estas variáveis na análise de redes sociais. Pensa-se resolver esta situaçáo num futuro próximo através da recolha e classificação de um maior número de dados.

Considera-se que a grande limitação encontrada na metodologia adoptada foi a ausência da espacialização da rede social construída. Todavia espera-se num futuro próximo que seja possível eliminar esta restrição através da experimentação de diferentes softwares que trabalhem na área da Análise de Redes Sociais.

\section{REFERÊNCIAS BIBLIOGRÁFICAS}

Brandes, U., Kenis, P. \& Wagner, D. 2003, "Communicating Centrality in Policy Network Drawings», Ieee Transactions on Visualization and Computer Graphics, vol.9, pp. 241-253.

Borgatti, S. P., Everett, M. G. e Freeman, L. C. 2002, "Ucinet for Windows: Software for Social Network Analysis», MA: Analytic Technologies, Harvard.

Câmara, G., Casanova, M., Hemerly, A., Magalhães, G., Medeiros, C. 1996, "Anatomia de Sistemas de Informação Geográfica.», Instituto de Computação, UNICAMP, Campinas.

Colomb, Claire 2007, «The added value of transnational Cooperation: Towards a new framework for evaluating learning and policy chance», Planning, practice \& research, vol.22, n.3, pp. 347-372.

Comunicação da Comissão aos Estados-Membros, de 7 de Maio de 2001, «A Cooperaçáo Inter-Regional Vertente C da iniciativa comunitária Interreg III», Comunicação da Comissão C (2001), 1188 final (2001/C 141/02).

Hanneman, R.A., Riddle, M., 2005, "Introduction to Social Network Methods», Riverside, CA: University of California, Riverside, disponível em: http://faculty.ucr.edu/ -hanneman/, [consultado em Setembro de 2009].

Interreg III C, disponível em: http://www.interreg3c.net/sixcms/detail.php?id=310, [consultado em Setembro de 2009].

Rivolin J., Faludi, A. 2005, "The Hidden Face of European Spatial Planning: Innovations in Governance», European Planning Studies, vol.13, n.2, pp.195-215. 